\title{
Ethical regulation and animal science: why animal behaviour is not so special
}

\author{
INNES C. CUTHILL \\ School of Biological Sciences, University of Bristol \\ (Received 13 March 2007; initial acceptance 7 April 2007; \\ final acceptance 17 April 2007; published online 6 June 2007; MS. number: E-3)
}

\begin{abstract}
Refinement, replacement and reduction of animals in research has become a guiding principle for legislation governing animal research, and for the implementation of that legislation. However, one of these '3Rs', replacement, would seem incompatible with the science of animal behaviour, where the animal is not a model for the human condition, but the object of interest itself. This, the power of biomedical research and the pharmaceutical industry as lobbying groups, and the fact that the public could come to equate 'animal research' with vivisection, should cause concern in the animal behaviour community. The dominance of the 3Rs, and the evaluation of the utility of animal research in terms of medical benefits, could come to dominate ethical decisions about animal research. I argue that the 3Rs are not as incompatible with the aims of animal behaviour as it first appears, and that their principles can be readily incorporated into our research, but this must be twinned with a greater commitment to dialogue with legislative bodies and biomedical lobbying groups, to ensure that the utility of animal research is not evaluated solely in terms of medical and other immediate human gains.
\end{abstract}

(C) 2007 The Association for the Study of Animal Behaviour. Published by Elsevier Ltd. All rights reserved.

Keywords: animal behaviour; animal experimentation; animal welfare; regulation; research ethics; the 3Rs

To many ethologists and behavioural ecologists, the debate over animal experimentation is one that takes place in another domain, with legislators seeking a difficult balance between a politicized animal rights movement and the might of the biomedical-pharmaceutical industry. Sometimes the Law and its accompanying bureaucracy must be faced, for example when mildly invasive procedures such as blood sampling are required, but the majority of studies that are published in journals such as Animal Behaviour involve procedures that slip below the threshold at which a legally binding document is required to sanction the research. However, because political, public and legal debate centres on licensed research, there are genuine fears that changes in legislation (or, importantly, the way legislation is interpreted) will have an unintended negative impact on the study of animal behaviour (Barnard 2007). In other words, animal behaviour will become a, largely unnoticed, casualty of laws seeking

Correspondence: I. C. Cuthill, Centre for Behavioural Biology, School of Biological Sciences, University of Bristol, Woodland Road, Bristol BS8 $1 U G$, U.K. (email: i.cuthill@bristol.ac.uk). a compromise between the needs of biomedical research and the public response to an opposing animal rights movement. An example of this would appear to be that replacement (of animals in research) is stated as the ultimate aim of the body set up by the U.K. government to oversee and promote laboratory animal welfare research: the National Centre for the Refinement, Replacement and Reduction of Animals in Research (NC3Rs; http:// www.nc3rs.org.uk/page.asp?id=4; the 3Rs themselves having been adopted from Russell \& Burch's 1959 classic text). This message is broadcast not only to a narrow audience of scientists and government agencies, but also to schoolchildren (e.g. Robinson 2005, page 2), and so could shape the views of the next generation of voters. To students of animal behaviour, however, nonhuman animals (henceforth 'animals') are not convenient model systems (for the study of human function) that can be replaced; they are the objects of study. The purpose of my article is to argue that the guiding principles of the 3Rs are not so incompatible with the aims of animal behaviour research as they at first appear. Furthermore, although animal behaviour does have a special role in informing the debate (Mason \& Mendl 1993; Dawkins 1998, 2003; 
Barnard 2007), it deserves no special exemptions from laws (understandably) shaped by what happens to the narrow range of laboratory-bred mammals used in biomedical research. That said, I agree completely with Chris Barnard (2007) that animal behaviour could suffer from its small footprint in the political arena, and the very fact that highly invasive and distressing procedures are rarely used. The worst thing that animal behaviourists can do is to distance themselves from the animal experimentation debate. Biomedically dominated lobbying groups may seem unwelcome bedfellows to many ethologists, but collaboration is a price worth paying to defend our freedom to do research, and to make a (moderating) voice heard in an increasingly polarized debate. My essay has a U.K. and European bias in terms of the specific legislation involved, for which I apologise, but the issues are, I hope, of wider interest.

\section{ANIMALS IN RESEARCH}

'The advancement of knowledge in biological or behavioural sciences' is not the only admissible reason for seeking permission to inflict legally pain, suffering or lasting harm on an animal. In the U.K.'s Animals (Scientific Procedures) Act it is number four on the list (Section 5(3) of the 1986 Act, http://www.archive.officialdocuments.co.uk/document/hoc/321/321-xa.htm). There are also justifications that involve no research, such as protection of the environment, postschool education and breeding for scientific use. In addition there are legally justifiable goals that are directly applied in their objectives and may (but do not have to) involve scientific experiments, such as forensic inquiries, and the prevention, diagnosis or treatment of disease, in humans and animals (or, in fact, plants). Similarly, the assessment, detection, regulation or modification of physiological conditions in humans and animals (again, or plants) need not involve scientific research, but can be legally legitimate grounds for justifying any consequent animal suffering.

When (and why) are animals involved in the 'advancement of knowledge' through science? When Christoph Scheiner (1619; reported, and explained, by Descartes 1637) dissected an ox's eyeball and observed an inverted image of the viewed scene projected on to the retina, he was not primarily interested in bovine vision. He was using the ox as a direct model of the human condition: more readily available and, on account of its size, easier to dissect than a human eye, but sufficiently anatomically similar to allow the extrapolation to be made. The use of animals as 'model humans' has one of the highest profiles in the debate on animal experimentation because it includes all uses of animals for toxicity and safety testing of nonveterinary drugs, food products and any chemical that humans may come into contact with (e.g. in cosmetics, although such testing has been banned in the U.K. since 1997), the assessment of the efficacy of drugs, practising surgical techniques and military research (in the U.K. for defensive purposes only). In ethology and behavioural ecology, it is rare to use animals as models of humans, although inferences about human sociobiology and psychology are frequently drawn, particularly from studying primates. In the wider behavioural sciences, animals (particularly rats and primates) are of course widely used as model humans in clinical studies of memory and learning.

Although foremost in the animal experimentation debate, in terms of total numbers of what the U.K. Home Office calls 'procedures' (loosely speaking, the numbers of animals times the number of things done to them), each of the above, directly applied, uses of animals have for some years been outnumbered by experiments aiming to understand fundamental biological processes (Table 26, Home Office 2006). However, even though the (usually medical) potential benefit to humans is further down the line, in most cases the animals are still used as a model system relevant to understanding human function. For example, in their Nobel Prize-winning work which uncovered the ionic mechanism of neural action potentials, Alan Hodgkin and Andrew Huxley performed experiments on the squid giant axon (e.g. Hodgkin \& Huxley 1952). This was not because they were primarily interested in the species itself but because the large diameter of the cell's axon provided a great experimental advantage; it allowed them to insert voltage clamp electrodes inside the lumen of the axon. This experimental preparation yielded a breakthrough in the accuracy to which action potential characteristics could be measured (Kandel et al. 2000).

Although the study of fundamental biological processes is distinct from research that directly claims human wellbeing as the target, in many biological disciplines the links to such benefits in the future are not hard to imagine. A deep understanding of vertebrate physiology and biochemistry, gleaned from animal research, underpins drug discovery and medical advice for a healthy lifestyle; genetics, functional genomics, proteomics and metabolomics promise even more in the future. Animals, however, are not only used for research that helps us understand human physiology and bodily, including mental, function; science also helps us understand other phenomena that affect humans. Human parasites are clearly animals worthy of study in their own right, for an immediate human benefit. Furthermore, for many human diseases and parasites, an animal is the vector, intermediate host, or a reservoir population (e.g. influenza and wildfowl; Baigent \& McCauley 2003). Then there is animal research directed at the well-being of the animals themselves, although, I would argue, the ultimate beneficiary that justifies the research is humankind. Research on growth, metabolism, reproduction, health and disease in livestock and working animals matters because their condition affects the health and economy of their producers, consumers and owners. Even veterinary research to improve the health and well-being of purely companion animals (pets) is ultimately justified by the fact that these animals matter to their owners for the emotional and other benefits they bring.

Successful conservation relies on a sound understanding of the biology of the organisms at risk and every other aspect of the ecosystem of which they are a part. We cannot hope to predict, or remedy, the effects of climate change, habitat degradation and fragmentation unless we 
understand the resources animals require, the predators, parasites and diseases that threaten them, how they compete and interact with sympatric species, and the sexual and social interactions necessary for successful breeding. Animal behaviour research has a central role here (Sutherland 1995; Festa-Bianchet \& Apollonio 2003) and, because the research and wildlife management methods may not be completely benign for the individual animals involved (e.g. trapping, tagging, translocation, captive breeding and reintroduction; see Cuthill 1991; Farnsworth \& Rosovsky 1993; Putman 1995; Powell \& Proulx 2003; Wilson \& McMahon 2006), an ethical judgement on the worth of the research must be made. Just as the use of animals in biomedical research is fundamentally 'species-ist' (Singer 1990; Ryder 2005; i.e. assumes, for example, that the life of a rat is worth less than that of a human), so too are many key conservation decisions. Rare endemics are often threatened by introduced species, and reversing the process by, usually terminal, removal of the invaders involves a value judgement that puts the life of, for example, an endangered New Zealand bird above that of an introduced, feral, domestic cat or rat (Bateson 2005).

When behavioural and ecological research for conservation purposes involves negative effects on the welfare of individual animals (say through capture and attachment of radiotransmitters), the benefits and likely success of the conservation effort itself must be assessed. Conservation itself is usually justified in terms of the benefits this brings to humans. Even here, biomedical utility is often at the forefront, with the pharmacological potential of tropical plant compounds highlighted (e.g. Schilthuizen 2006). More generally, conservation is 'sold' on the potential future need for the nonrenewable (or hard to renew) resources that a threatened habitat may contain or, in an even more directly utilitarian fashion, the 'biosphere services' they currently provide (Balvanera et al. 2001; Balmford et al. 2002), such as the role of rainforests as a carbon sink. Tellingly, although a prime motivator for individuals that support and fund conservation organizations, saving a species because it is simply a beautiful or amazing animal (or plant) is rarely used in arguments directed at national governments or supranational legislators. Instead, the benefits of saving high-profile species such as tigers and orang-utans are more often sold to governments and financiers on the (valid) argument that they are key indicators of the status of the whole habitat that supports them (which may act in climate homeostasis, or contain plants of biomedical utility, etc.).

\section{THE UTILITY OF SCIENTIFIC RESEARCH ON ANIMALS}

It is clear from the above that the simplest and most widely used argument for researching fundamental biological processes is that there may be a deferred benefit to humans. For example, the Royal Society's policy statement on the benefits of animal research says 'although a significant proportion of work using animals is basic research whose benefits to health are not immediately evident, this work is highly valuable as it provides the groundwork for future medical advances' (Bateson et al. 2004, page 1). Given that this statement comes from the organization that is often regarded as the voice of British science, the word 'medical' is understandable, but unfortunate. As Barnard (2007) argues correctly, equating human utility with biomedical advances creates a hostage to fortune, because there is the danger that nonmedical benefits come to be considered less important, or even unimportant. Yet, as I have outlined above, there are lots of valid, entirely utilitarian benefits for animal research that have nothing to do with disease or combating human pathologies. With climate change highlighted as the single greatest problem facing humanity, and effects on animal life history and behaviour a central component of ecosystem function, one can easily argue that there are even more important utilitarian concerns than human health and disease. However, I have left one utilitarian benefit to last, one that drives my own scientific career and that of many (most?) other scientists: satisfying curiosity. Within the realm of biology, scientific curiosity used to be justified as a route to understanding the Mind of God based, for example, on William Paley's (1743-1805) argument from design (Paley 1802). Such early 'intelligent design' arguments made compatible Darwin's choice of a theology degree with his career aspirations in natural history (Desmond \& Moore 1991). Because Charles Darwin provided nonsupernatural explanations for both apparent design (adaptation) and organic diversity, one is left with curiosity for curiosity's sake. The wonders of nature are no less wonderful or mysterious (Dawkins 1986, 2006; Dennett 1995), but how can plain curiosity be defended as a utilitarian argument for doing science?

The word utilitarian was used by Jeremy Bentham (1748-1832) to describe the doctrine where social choice is guided by the greatest happiness for the greatest number (Gunn 1989). However, rather than being calculated in units of 'happiness', utility is a value that is usually equated with usefulness or practicality as opposed to beauty or aesthetics. This definition probably says a lot about British attitudes to work and pleasure and, within evolutionary biology, this antipathy between the quest for sensible material resources and attraction to frivolous beauty appears in the sexual selection literature: Wallace versus Darwin, Zahavi versus Fisher, 'good genes' versus 'sexy sons' (Cronin 1991). Modern sexual selection theory, however, sees this as a false dichotomy (Kokko et al. 2003); enhanced mating success through greater beauty is as utilitarian as that obtained by enhanced parasite resistance, and the trade-off between the different fitness components determines where the balance lies. So, in biology it can be difficult (indeed inappropriate) to view aesthetic and other less tangible benefits as distinct from, and opposed to, utilitarian benefits. In economics too, the technical term 'utility' is used to quantify the subjective value people ascribe to resources regardless of their material worth (e.g. Mas-Colell et al. 1995; Kacelnik 2006). If value could be measured objectively, in terms of importance to survival or financial gain, then the subjective concept of utility would never have been erected. To scientists, the drive to understand and explain, 
satisfying curiosity for curiosity's sake, has extremely high subjective value; they have devoted their lives to this, but scientists are merely those humans who have been lucky enough to turn the basic human instinct of curiosity into a career. It is that instinct that led to technology and global expansion so, for good or ill, it is a human attribute that has underpinned our success as a species. Although funders of science may shy away from such justifications, it is up to us a scientists, to convince them that the public may not be as unresponsive to the benefits of pure research as funders and governments may think. The study of animal behaviour has huge public appeal based on human curiosity rather than the material benefits it may bring.

\section{THE COSTS OF USING ANIMALS IN SCIENCE}

So Science uses animals, but sometimes at a cost. These include costs to the animal such as the pain, suffering, distress or lasting harm that animal welfare legislation declares illegal and is acceptable only in certain, carefully regulated, contexts, of which scientific research can be one. This essay is not the place to discuss why we have any moral concern for animals in the first place; all that matters for the present purpose is that in a society that respects animals, these are important costs to consider. Premature death could also be a cost to be evaluated although, provided that the process is humane, it is not a cost that European law considers relevant (except in as far as, for wild animals, nature protection legislation comes into play or, if the animal is someone's property, the owner's rights may be protected in this respect; Cooper 1987). However, there may be other costs to scientific research on animals, beyond those inflicted on the animal itself: ecological, psychological and social costs. By 'ecological', I mean effects on the rest of the animal's population, the other species with which it naturally interacts, and the environment itself. Ecological costs are not an issue with laboratory research on captive-bred animals, but can arise when animals are taken from the wild, and with field-based research. Such impacts have been reviewed elsewhere (Cuthill 1991; Farnsworth \& Rosovsky 1993; Putman 1995; Powell \& Proulx 2003; Wilson \& McMahon 2006), but could include stress, injury or death of nontarget species through nonspecific capture methods (e.g. mist nets, pitfall traps), habitat disturbance by the experimenter, attraction and better access to the study area for predators or human hunters, and disruption of social networks and population genetic structure through removal (and subsequent release) or translocation.

Psychological costs are the effects on the experimenter him- or herself, as a result of doing the research. The possibility that causing suffering to others can psychologically damage the perpetrator lies behind 'agent-centred' approaches to ethics and morality. While the concern is for the state of the person causing the suffering, there is a wider social interest at heart. If someone can rationalize causing pain or suffering to an animal (or, worse still, enjoys the process), there is the worry that he or she might one day rationalize doing the same to another human.
Following concern for the animal itself, the next common reaction to a photo of an animal that has experienced human cruelty is 'what sort of person could do that?' This should not apply to scientific research on animals, because we are not talking about wanton cruelty for personal pleasure, and it is not left to the individual scientist to establish the acceptable boundaries and evaluate the costs and benefits. Nevertheless any scientist who carries out research that might cause pain or distress to an animal should personally confront whether it is justified, and that can be emotionally taxing, something that the militant animal rights movement plays on. This brings us to the social costs of doing animal research. At the extreme, if some people deem a particular line of research sufficiently unacceptable that they are prepared to carry out acts of terrorism directed at the friends and family of the scientist, then that becomes part of the cost-benefit analysis the scientist must evaluate before doing that research, as do the knock-down effects of campaigns targeting the suppliers of animals and ancillary resources (e.g. constructors of research laboratories). More subtly, if adherence to the legislation surrounding the research becomes sufficiently onerous, then that alone affects the willingness of an individual scientist to pursue a line of research.

\section{GETTING THE BALANCE RIGHT}

In the case of the ecological, psychological and social costs, it is not hard to see why a scientist, or the society approving the research, should take these into account when considering whether the scientific benefits are worthwhile. There is direct or deferred self-interest involved. The value attached to the welfare, or life, of the individual animal is harder to specify because it is a social construct. Some societies consider all life sacred, others view animals as resources. In the U.K. although there is some attempt to relate the capacity for suffering to neurobiological complexity, it really comes down to those species with which there is some empathy. Although alternative, more objective, models for evaluating the capacity for suffering exist (e.g. Dawkins 1990, 1998; Barnard \& Hurst 1996), the animals given special protection in U.K. law are those that look like us (primates) or have a long history as companion animals (cats, dogs, horses). But whatever the mixture of historical accident and scientific knowledge that contributes to the current valuation of a given research animal's life and quality of life, what mechanism can be used to evaluate its worth against any deleterious effects of the research to be carried out on it?

Current European law adopts a utilitarian stance: the needs of the many can justify costs to the one, whether it is a nonhuman animal, a human or, indeed, an inanimate object. A national park or 'green belt' is defended from urban development as long as the current utility (social value) of the area for recreation, and its potential for future uses as yet unrealized, outweigh the benefits of increased housing and income generation. Individual freedoms are routinely restricted for the greater good of 
society (freedom to kill, steal, insight racial hatred, etc.). Individual rights are suspended if one breaks the law, in times of war, or young age or mental illness precludes a full understanding of the 'social contract' one is signed up to as a member of society. Animals cannot enter into the social contract (explain to a lion why it is wrong to kill) but, like children and the mentally ill, are accorded certain rights, including freedom from pain, suffering, distress or lasting harm.

In the utilitarian framework, suspension of an animal's rights to freedom from pain, suffering, distress or lasting harm can be justified only if there is a contravening 'greater good'. This is at direct odds with ethical frameworks that give individual rights primacy ('the needs of the many can never justify costs to the one'), and this philosophical debate underpins the antipathy between the animal rights movement and the status quo. The utilitarian approach is what currently guides decision making in animal research and, indeed, democratic society. The utility assigned to protecting the animal's rights is a social construct, but no less important for that. In fact, the utility assigned to scientific research is a social construct too. Cures for cancer, relief from pain, reduced child mortality, may all seem like 'real' currencies, and more tangible than satisfying curiosity in the pursuit of knowledge, but the absolute and relative values attached to each are social constructs that differ from society to society, and through history. Nevertheless, at a given point in time, each society must arrive at the preferred balance between the potentially conflicting utilities of animal rights and human needs. The dominant model shaping U.K. and EU legislation, and the way the law is put into effect (e.g. Home Office 2000), has been heavily influenced by a particular decision framework popularized by Patrick Bateson (Bateson 1986, 2005).

'Bateson's cube' seeks to establish the position of a piece of research in three dimensions: the costs to the animal, the importance of the research and the quality of results. In the original paper (Bateson 1986) and in subsequent accounts (e.g. Bateson et al. 2004), the importance of the research is, perhaps unfortunately, equated with likely medical benefits (Emlen 1993). This is understandable, because our society generally values medical benefits highly (we don't like pain, we want a long and healthy life), but the medical benefits axis is readily relabelled as utility, defined widely, as earlier, so Bateson's cube remains a valuable decision tool. Bateson himself stresses that it is a tool for making judicial decisions and not a formal model to determine the optimal trade-offs, because of the difficulty in expressing the three axes in a common currency (statement 1025, House of Lords Select Committee on Animals in Scientific Procedures 2002; Bateson 2005). In Bateson's cube, the ideal is that research should have high value, be of high quality, and cause the minimum costs to the experimental animal. Research with a cost to the animal in terms of pain, suffering or lasting harm can be sanctioned, but only if the likely benefits are high and the quality of the research sufficient to make advances likely. One should always be looking to move research towards the high-quality, high-benefit, low-cost region of the space, and one way of doing that is through Refinement, Replacement and Reduction.

\section{CAN WE REFINE, REPLACE AND REDUCE IN ANIMAL BEHAVIOUR RESEARCH?}

\section{Refinement}

Refinement is the use of methods that alleviate or minimize potential pain, suffering or distress, and that improve welfare for those animals that do need to be used.

Refinement of experimental procedures for these ends would seem to be an uncontroversial aim for any researcher, with the win-win payoff of better welfare for the animal and, as a likely result, higher quality data for the scientist. Refinement is evident in behavioural research where, for example, faecal hormone assays replace blood sampling (Buchanan \& Goldsmith 2004; Touma \& Palme 2005), identification from natural markings replaces physical tags (e.g. Pennycuick 1978; Kelly 2001) and short-term surrogates of fitness, in response to short-term manipulations, are used in preference to changes in survival in response to permanent manipulation. Easy-to-measure short-term currencies (e.g. energy intake rate, provisioning rate, mating rate) have always been the stock-in-trade for behavioural ecology (Stephens \& Krebs 1986; Krebs \& Davies 1993), but this has historically been driven, not by welfare considerations, but by the difficulty of measuring 'true fitness' in the wild, relatively long-lived, organisms frequently studied. A near-fitness measure, such as survival or lifetime reproductive success has always been the preferred currency because, ultimately, an adaptive explanation seeks to uncover the means by which the trait under study affects fitness (Thornhill 1990; Cuthill 2005), but this can create a problem for animal welfare, because a change in fitness may result from a change in the probability of survival, and death may not come swiftly and painlessly.

Take the classic experiment, repeated hundreds of times, to investigate optimal clutch size in birds, itself a landmark paradigm for the study of life history trade-offs (Godfray et al. 1991). Following Lack (1947), the optimal clutch size is predicted to be adjusted to the number of young the parent(s) can adequately feed (perhaps, in subsequent theoretical treatments, moderated by costs to the parent itself; reviewed in Daan \& Tinbergen 1997). Natural variation cannot unambiguously determine the causal influence of clutch size on growth and survival of the chicks, nor the costs to the parent, so good science demands that a manipulation of clutch size must be carried out. The 'best' experiments in this genre quantify survival of young to fledging, survival to breed in the following and/or subsequent years, any effects of nestling food intake on size and reproductive opportunities at adulthood, and similar effects on parental survival and reproduction opportunities. As reduced survival as a nestling is likely to be effected through starvation or, in some species, reduced ability to resist siblicidal attacks by nestmates, and reduced survival after fledging may result from a compromised ability to resist parasites and diseases, this type of 
experiment diminishes individual welfare. Such death and suffering occur naturally, and one could argue that the experimenter is merely redistributing these costs, but that does not absolve the experimenter of responsibility, because the effects have occurred under the experimenter's 'dominion' (Cuthill 1991; Bekoff \& Hettinger 1994).

With accumulated species-specific knowledge of the relation between feeding rate, growth, immunocompetence and survival, refinement may be possible: short-term manipulations and a return to 'normal' after short-term measures of response have been taken. However, there is an important caveat. If the relations between short-term surrogate currencies and long-term fitness are not well characterized, 'refinement' may not be well served by the short-term manipulation approach. Although the cost to the individual animals in any one experiment may be reduced, if such data do not get to the heart of the scientific question being addressed (the 'quality of results' axis in Bateson's cube), there may need to be further experiments, possibly with greater welfare costs (better measures of fitness), and so ultimately a higher welfare price. A judgement must be made as to whether science and welfare are better served by a single definitive experiment with higher costs to the subjects, than a series of experiments, involving lower welfare costs but more animals, and that do not provide clear answers (Emlen 1993).

Refinement can also be achieved outside of the experiment itself, by improved housing and husbandry of laboratory animals (a growing literature that supports the journals Laboratory Animals and Animal Welfare, and numerous papers in general behaviour journals), and for field studies, reduced impact on the social and physical environment (Cuthill 1991; Farnsworth \& Rosovsky 1993; Putman 1995). Besides the imperative on animal behaviour scientists to improve welfare and husbandry for their own research animals, studies of behaviour should play a central role in informing best practice. This is because animal behaviour science is uniquely placed to shift current practice from anthropomorphic notions of what is best for the animal, to what the animals actually need (Barnard \& Hurst 1996; Barnard 2007).

\section{Replacement}

In biomedical research, replacement involves the use of methods such as cell cultures, human volunteers and computer modelling instead of animals. The goal of replacement of animals in research may, if one is optimistic, be achievable one day for the, often clinical, studies that use animals only as models of the human condition, but surely it is anathema to animal behaviour, where the animal itself is the object of study? In fact, replacement is not such an absurd goal, once we remember the target of the 3Rs as understood by the Home Office and the NC3Rs. First, it is replacement of animals in research that has the potential to cause pain, suffering, distress or lasting harm, that is, not all animal research, but research requiring a Home Office licence in the U.K., or comparable legally binding control elsewhere. Second, because the 3Rs refer to animals protected in Law, we have to remember what an animal is in the eyes of the Law. As defined in EU Council Directive 86/609/EEC of 24 November 1986, instantiated in the U.K. via the 1986 Animals (Scientific Procedures) Act (ASPA), a protected animal is any live nonhuman vertebrate, including free-living larval and/or reproducing larval forms, but excluding fetal or embryonic forms before a specified stage of development. In the U.K. we add Octopus vulgaris (just the common octopus), but there is active consideration of including other cephalopods as 'protected animals' (Animal Procedures Committee 2006, pp. 15-16). Indeed, the U.K. legislation adds the rider that the Secretary of State may by order extend the definition... to include invertebrates of any description', although it is not clear whether this extension has ever been applied. A consequence of this restricted definition of animals protected in Law is that research on most invertebrates, and indeed larval fish and amphibians before they are capable of feeding themselves, is not animal research in the eyes of the Law.

So, replacement is possible in animal behaviour research: replace 'animal' as defined in ASPA with a 'nonanimal', i.e. noncephalopod invertebrate; or replace a regulated procedure on a vertebrate with a nonregulated procedure on the same animal. Given that behavioural ecology, at least, is a discipline driven by general theory rather than taxon-specific interest (Cuthill 2005), there need be few costs in replacing a mammal or bird with an arthropod. For example, if parental care and parentoffspring communication are of interest, burying beetles may be able to answer many of the questions usually addressed with birds (e.g. Smiseth \& Moore 2004). If the balance between cooperation and conflict in society is the motivation for research, may be an ant or slime mould is as good a model as a meerkat for defining fundamental principles?

In biomedical research, models are widely touted and used as replacements for animal experiments. Models are of course widely used in animal behaviour; indeed they are the most powerful tool available for investigating function (Thornhill 1990; Cuthill 2005). For this reason, unlike in biomedical research, models are rarely used as a simulation tool to mimic real behaviour, rather as an essential part of the scientific process alongside animal experiments; but because functional models are a guide to more directed research questions and an essential tool for interpreting the results of experiments, they contribute, in the medium-to-long-term, to replacement.

\section{Reduction}

Reduction in animal use is achieved through refinement of research strategy as opposed to refinement of specific experimental procedures. Factors that lead to more focused research questions, such as a theory (and model)-led research programme, and use of model species for which lots of background knowledge is available, contribute to more informative single experiments and so the need for fewer regulated procedures in the long term. A major contributor is better experimental design and correct use 
of the most powerful statistical tests available, both issues on which animal behaviourists are reasonably well informed (witness the fact that Animal Behaviour regularly features papers on statistics and experimental design). However, animal behaviourists should be wary of a contributor to greater statistical power that is routinely promoted in biomedical research: increasing power through reduction of between- and within-subject variability (Festing 2004a, b), itself achieved through use of inbred strains, a single sex (usually male, to avoid the changes that accompany oestrous cycles in females) and constant environmental conditions. Zuk (1993) has drawn attention to the bias created by a biomedical literature in which the vast majority of experiments have been conducted on (only) male rodents, but the problem is far more general. The trouble with the results from, say, an experiment on male $\mathrm{BALB} / \mathrm{c}$ mice conducted at $24^{\circ} \mathrm{C}$ and $60 \%$ relative humidity is that the results only generalize to male BALB/c mice at $24^{\circ} \mathrm{C}$ and $60 \%$ relative humidity; a gain in power is achieved at a tremendous loss of external validity (Mook 1983; Anderson et al. 1999; Würbel 2000). Standardization strengthens the evidence for processes that may apply, but weakens evidence for the range of circumstances to which they actually do apply. The very problems that reduce power in, particularly, field experiments, such as heterogeneous subjects and varied and varying environmental conditions, are their very strength; the results generalize to the natural conditions about which inferences are sought (Cuthill 2005).

There is, however, a reason to believe that better science in animal behaviour research will probably call for an increase, not a reduction, in animal numbers (although not necessarily in experiments where there might be adverse welfare). The subject is still dominated by the classical statistical tradition of null hypothesis significance testing, with belief or otherwise in an effect being dictated by on which side of 0.05 the $P$ value falls. The dominant focus in modern statistics, increasingly adopted in other disciplines, is on precise assessment of the effect size, not a binary assessment of whether that effect size might be zero (Yoccoz 1991; Nickerson 2000; Kline 2004). Jennions \& Møller (2003), in a meta-analysis of the statistical power of experiments in behavioural ecology, concluded that the majority have only low to medium power. The only way that this can be reconciled with the fact that these same experiments are mainly statistically significant is if there is a bias in favour of publishing positive results (Bauchau 1997; Palmer 1999, 2000) or a bias in selection of study systems or conditions likely to produce significant results. Palmer (2000) offers a good piece of advice for authors, referees and editors when seeking to publish a significant result: would you believe the results if they were nonsignificant? Such an approach, or better still a focus on discriminating between competing hypotheses through precise estimates of effect size, will require not only an increase in animal numbers but also a change of culture. Whether this can be achieved within the 3Rs will depend on behavioural scientists' will to adopt nonvertebrate model systems and/or refinements to techniques used with vertebrates: a challenge surely worth meeting. However, as Barnard (2007) argues, this whole- hearted adoption of the 3Rs as a guiding principle must be twinned with a constant dialogue with the legislative and political bodies, to ensure that they are aware of the utility of pure behavioural research on animals.

\section{Acknowledgments}

The views expressed are entirely those of the author and do not represent the views of any institution, professional society or other body. Many thanks to Pat Bateson, Max Headley, Mike Mendl and an anonymous referee for their comments on the manuscript.

\section{References}

Anderson, C. A., Lindsay, J. J. \& Bushman, B. J. 1999. Research in the psychological laboratory: truth or triviality? Current Directions in Psychological Science, 8, 3-9.

Animal Procedures Committee. 2006. Report of the Animal Procedures Committee for 2005. London: The Stationery Office.

Baigent, S. J. \& McCauley, J. W. 2003. Influenza type A in humans, mammals and birds: determinants of virus virulence, host-range and interspecies transmission. BioEssays, 25, 657-671.

Balmford, A., Bruner, A., Cooper, P., Costanza, R., Farber, S., Green, R. E., Jenkins, M., Jefferiss, P., Jessamy, V., Madden, J., Munro, K., Myers, N., Naeem, S., Paavola, J., Rayment, M., Rosendo, S., Roughgarden, J., Trumper, K. \& Turner, R. K. 2002. Ecology: economic reasons for conserving wild nature. Science, 297, 950-953.

Balvanera, P., Daily, G. C., Ehrlich, P. R., Ricketts, T. H., Bailey, S. A., Kark, S., Kremen, C. \& Pereira, H. 2001. Conserving biodiversity and ecosystem services. Science, 291, 2047.

Barnard, C. J. 2007. Ethical regulation and animal science: why animal behaviour is special. Animal Behaviour, 74, 5-13.

Barnard, C. J. \& Hurst, J. L. 1996. Welfare by design: the natural selection of welfare criteria. Animal Welfare, 5, 405-433.

Bateson, P. 1986. When to experiment on animals. New Scientist, 109, 30-32.

Bateson, P. 2005. Ethics and behavioural biology. Advances in the Study of Behavior, 35, 211-233.

Bateson, P., Biggs, P., Cuthbert, A., Cuthill, I., Festing, M., Keverne, E. B., King, S., Page, C., Petersen, O., Rothwell, N., Rushworth, M., Walsh, V. \& Roberts, O. 2004. The Use of Nonhuman Animals in Research: a Guide for Scientists. The Royal Society, Policy Document 01/04. London: The Royal Society.

Bauchau, V. 1997. Is there a 'file drawer problem' in biological research? Oikos, 79, 407-409.

Bekoff, M. \& Hettinger, N. 1994. Animals, nature, and ethics. Journal of Mammalogy, 75, 219-223.

Buchanan, K. L. \& Goldsmith, A. R. 2004. Noninvasive endocrine data for behavioural studies: the importance of validation. Animal Behaviour, 67, 183-185.

Cooper, M. E. 1987. An Introduction to Animal Law. London: Academic Press.

Cronin, H. 1991. The Ant and the Peacock. Cambridge: Cambridge University Press.

Cuthill, I. C. 1991. Field experiments in animal behaviour: methods and ethics. Animal Behaviour, 42, 1007-1014.

Cuthill, I. C. 2005. The study of function in behavioural ecology. Animal Biology, 55, 399-417.

Daan, S. \& Tinbergen, J. 1997. Adaptation of life histories. In: Behavioural Ecology. An Evolutionary Approach. 4th edn. (Ed. by 
J. R. Krebs \& N. B. Davies), pp. 311-333. Oxford: Blackwell Science.

Dawkins, M. S. 1990. From an animal's point of view: motivation, fitness and animal welfare. Behavioral and Brain Sciences, 13, 1-61.

Dawkins, M. S. 1998. Evolution and animal welfare. Quarterly Review of Biology, 73, 305-328.

Dawkins, M. S. 2003. Behaviour as a tool in the assessment of animal welfare. Zoology, 106, 383-387.

Dawkins, R. 1986. The Blind Watchmaker. Harlow: Longman.

Dawkins, R. 2006. The God Delusion. London: Bantam Press.

Dennett, D. C. 1995. Darwin's Dangerous Idea. New York: Simon \& Schuster.

Descartes, R. 1637. Discours de la Méthode pour Bien Conduire sa Raison, et Chercher la Verité dans les Sciences. Plus la Dioptrique, les Meteores, et la Geometrie. Available at Project Gutenberg http://www.gutenberg.org/wiki/Main_Page.

Desmond, A. \& Moore, J. 1991. Darwin. London: Penguin

Emlen, S. T. 1993. Ethics and experimentation: hard choices for the field ornithologist. Auk, 110, 406-409.

Farnsworth, E. J. \& Rosovsky, J. 1993. The ethics of ecological field experimentation. Conservation Biology, 7, 463-472.

Festa-Bianchet, M. \& Apollonio, M. (Eds) 2003. Animal Behavior and Wildlife Conservation. Washington DC: Island Press.

Festing, M. F. W. 2004a. Good experimental design and statistics can save animals, but how can it be promoted? Alternatives to Laboratory Animals, 32, 133-135.

Festing, M. F. W. 2004b. Refinement and reduction through the control of variation. Alternatives to Laboratory Animals, 32, 259263.

Godfray, H. C. J., Partridge, L. \& Harvey, P. H. 1991. Clutch size. Annual Review of Ecology and Systematics, 22, 409-429.

Gunn, J. A. W. 1989. Jeremy Bentham and the public interest. In: Modern Political Theory from Hobbes to Marx: Key Debates (Ed. by J. Lively \& A. Reeve), pp. 199-219. London: Routledge.

Hodgkin, A. L. \& Huxley, A. F. 1952. Currents carried by sodium and potassium ions through the membrane of the giant axon of Loligo. Journal of Physiology, 116, 449-472.

Home Office. 2000. Guidance on the Operation of the Animals (Scientific Procedures) Act 1986. HC 321. London: The Stationery Office.

Home Office. 2006. Statistics of Scientific Procedures on Living Animals Great Britain, 2005. London: The Stationery Office.

House of Lords Select Committee on Animals in Scientific Procedures. 2002. Minutes of Evidence. London: The Stationery Office.

Jennions, M. D. \& Møller, A. P. 2003. A survey of the statistical power of research in behavioral ecology and animal behavior. Behavioral Ecology, 14, 434-445.

Kacelnik, A. 2006. Meanings of rationality. In: Rational Animals? (Ed. by S. Hurley \& M. Nudds), pp. 87-106. Oxford: Oxford University Press.

Kandel, E. R., Schwartz, J. H. \& Jessell, T. M. 2000. Principles of Neural Science. 4th edn. New York: McGraw-Hill.

Kelly, M. J. 2001. Computer-aided photograph matching in studies using individual identification: an example from Serengeti cheetahs. Journal of Mammalogy, 82, 440-449.

Kline, R. B. 2004. Beyond Significance Testing. Washington DC: American Psychological Association.

Kokko, H., Brooks, R., McNamara, J. M. \& Houston, A. I. 2003. The sexual selection continuum. Proceedings of the Royal Society of London, Series B, 269, 1331-1340.

Krebs, J. R. \& Davies, N. B. 1993. An Introduction to Behavioural Ecology. 3rd edn. Oxford: Blackwell Science.
Lack, D. 1947. The significance of clutch size. Ibis, 89, 302-352.

Mas-Colell, A., Whinston, M. \& Green, J. 1995. Microeconomic Theory. Oxford: Oxford University Press.

Mason, G. J. \& Mendl, M. 1993. Why is there no simple way of measuring animal welfare? Animal Welfare, 2, 301-309.

Mook, D. G. 1983. In defense of external invalidity. American Psychologist, 38, 379-389.

Nickerson, R. S. 2000. Null hypothesis significance testing: a review of an old and continuing controversy. Psychological Methods, 5, 241-301.

Paley, W. 1802. Natural Theology. Reprinted 2006, with an introduction and notes by M.D. Eddy \& D.M. Knight. Oxford: Oxford University Press.

Palmer, A. R. 1999. Detecting publication bias in meta-analysis: a case study of fluctuating asymmetry and sexual selection. American Naturalist, 154, 220-233.

Palmer, A. R. 2000. Quasireplication and the contract of error: lessons from sex ratios, heritabilities and fluctuating asymmetry. Annual Review of Ecology and Systematics, 31, 441-480.

Pennycuick, C. J. 1978. Identification using natural markings. In: Animal Marking: Recognition Marking of Animals in Research (Ed. by B. Stonehouse), pp. 147-159. London: MacMillan.

Powell, R. A. \& Proulx, G. 2003. Trapping and marking terrestrial mammals for research: integrating ethics, performance criteria, techniques, and common sense. ILAR Journal, 44, 259-276.

Putman, R. J. 1995. Ethical considerations and animal welfare in ecological field studies. Biodiversity and Conservation, 4, 903-915.

Robinson, V. 2005. Finding alternatives: an overview of the 3 Rs and the use of animals in research. School Science Review, 87, 111-114.

Russell, W. M. S. \& Burch, R. L. 1959. The Principles of Humane Experimental Technique. London: Methuen.

Ryder, R. 2005. All beings that feel pain deserve human rights. Equality of the species is the logical conclusion of post-Darwin morality. The Guardian, 6 August, 2005.

Schilthuizen, M. 2006. Biodiscoveries. Borneo's Botanical Secrets. Jakarta: WWF International.

Singer, P. 1990. Animal Liberation. 2nd edn. New York: Random House.

Smiseth, P. T. \& Moore, A. J. 2004. Signalling of hunger when offspring forage by both begging and self-feeding. Animal Behaviour, 67, 1083-1088.

Stephens, D. W. \& Krebs, J. R. 1986. Foraging Theory. Princeton, New Jersey: Princeton University Press.

Sutherland, W. J. 1995. From Individual Behaviour to Population Ecology. Oxford: Oxford University Press.

Thornhill, R. 1990. The study of adaptation. In: Interpretation and Explanation in the Study of Behavior (Ed. by M. Bekoff \& D. Jamieson), pp. 1-31. Boulder, Colorado: Westview Press.

Touma, C. \& Palme, R. 2005. Measuring fecal glucocorticoid metabolites in mammals and birds: the importance of validation. Annals of the New York Academy of Sciences, 1046, 54-74.

Wilson, R. P. \& McMahon, C. R. 2006. Measuring devices on wild animals: what constitutes acceptable practice? Frontiers in Ecology and the Environment, 4, 147-154.

Würbel, H. 2000. Behaviour and the standardization fallacy. Nature Genetics, 26, 263.

Yoccoz, N. G. 1991. Use, overuse, and misuse of significance tests in evolutionary biology and ecology. Bulletin of the Ecological Society of America, 72, 106-111.

Zuk, M. 1993. Feminism and the study of animal behavior. BioScience, 43, 774-778. 